\title{
INVESTIGATION OF THE SHIELDING CAPABILITY OF CONCRETE MATRIXED COLEMANITE REINFORCED SHIELDING MATERIAL
}

\author{
Tuncay Tuna ${ }^{a^{*}}$, Kübra Bayrak ${ }^{b}$ \\ $a^{*}$ TAEK, Cekmece Nuclear Research and Training Center, Istanbul, Turkey \\ tuncaytuna26@gmail.com (corresponding author) \\ ${ }^{b}$ Yıldız Technical University, Istanbul, Turkey \\ bayrakkbra@gmail.com
}

\begin{abstract}
In this study, neutron shielding capabilities of colemanite reinforced materials with concrete matrix were investigated. Containing $70 \%$ by weight of colemanite a boron compound 20,40 and $60 \mathrm{~mm}$ samples were prepared and their neutron shielding properties were studied. Composite material prepared by hand mixing by the weight of different ratios of colemanite, so that the obtaining process of the samples are extremely smooth. As an excellent thermal neutron absorber, colemanite is the crucial part of the composite. Beside this, concrete act as a role of thermalizing the energetic neutrons, by the way the colemanite can absorb the particles. It was observed that shielding capability of the composite material increased with increasing its thickness. The performance of neutron radiation shielding of specimens prepared by adding $70 \%$ colemanite by weight into concrete material was experimentally analyzed with Am-Be neutron source measurement system.
\end{abstract}

Keywords: Neutron radiation, shielding, composite material, colemanite, concrete

\section{Introduction}

Radiation is a reality that has become an inevitable part of our daily life and studies with this phenomena such as medicine, industry, education, and R\&D fields have opened doors to developments that will benefit many people. However, radiation has the ability to threaten the health of living organisms when exposed uncontrollably. That's why the crucial thing to do is shielding to protect from the harmful effects of radiation.

Neutron radiation shielding has been worked with varied materials from the past to the present day and different shielding materials have been developed and tested. In a large part of recent works composite materials are mostly preferred. The main target in shielding studies prepared 
with polymer and metal matrix composite materials is that thermalizing the neutrons with the light nucleus in the matrix then absorbing the thermalized neutrons with high thermal neutron cross sectioned reinforcement material [1]. Lightweight shielding products can be produced with polymer matrix materials while metal matrixed shielding materials with high strength can be obtained [2]. The concrete matrix used in our work is preferred in shielding experiments which are desired to be done without using additional thermalizing systems especially in fast neutron studies. Concrete's hydrocarbon content does not only slow the fast neutrons in the material, but also provides shielding against secondary gamma rays due to its high density [3]. The easily available and manufacturable concrete, is an inexpensive and efficient matrix material that can be used in shielding studies where restrictions such as weight are not so crucial. The colemanite added to the concrete matrix is a boron compound which preferred in neutron shielding studies. As known, boron is an excellent material with its mechanical values [4]. In addition, the world's total boron reserves are 1.3 billion tons; Turkey has $72.8 \%$ of this reserve, so it is unrivaled in terms of Turkey's boron mineral asset [5]. In the literature, beside the radiation shielding properties of the shielding materials, various characteristics such as mechanical strength values are determined.

In the shielding study of the ultra-fast neutrons, the behaviors of concrete samples containing $\mathrm{Fe}-\mathrm{B}$ and $\mathrm{B}_{4} \mathrm{C}$ reinforcing materials were investigated with using the Fluka Monte Carlo code. The targetted dose value is less than $0,1 \mu \mathrm{Sv} / \mathrm{h}$ for the public area. According to the simulation results; without reinforcement material the dose limits can be reached with $650 \mathrm{~cm}$ thick concrete samples. This value decreased to $610 \mathrm{~cm}$ with $20 \% \mathrm{~B}_{4} \mathrm{C}$ reinforcement. For the $20 \%$ $\mathrm{Fe}-\mathrm{B}$ reinforcement, it was observed at $490 \mathrm{~cm}$. Based on these data, $\mathrm{Fe}-\mathrm{B}$ reinforced concrete is recommended for fast neutron shielding [6]. $\mathrm{B}_{4} \mathrm{C}$ and paraffin (Wax), $0.30 \mathrm{~mm}, 0.55 \mathrm{~mm}$ and $0.65 \mathrm{~mm}$ thickness specimens were prepared and according to neutron shielding test results it was observed that the thickest specimen had the most neutron shielding ability. However, the difference between the results is negligible. It is stated that the reason for these minor differences is that the sample thicknesses are selected very close to each other. Also, according to the comparison made with other studies, it has been stated that the $\mathrm{B}_{4} \mathrm{C}$ reinforced samples give better shielding values than the kurnakovite and inderite [7]. ${ }^{10} \mathrm{~B}$ reinforced concrete shielding material was developed, it was observed that as the amount of borax added to the prepared cement increased, there was not much change in neutron permeability with increasing gamma shielding [8]. The CS-516, SS403, SS410, SS316, SS316L, SS304L, Inconel600, Monel400 and Copper-Nickel alloys have been investigated against gamma and neutron radiation in some metal alloys that are frequently used in reactors. It has been worked with fast neutrons and gamma rays. While SS316 stands out against the neutrons, copper-nickel alloys against gamma radiation emerges from within other metals and alloys [9]. Shielding tests with colemanite, ulexite and tincal ores have been simulated with FLUKA Monte Carlo code and then it was found that the neutron permeability decreased according to the amount of boron in the prepared samples and that the ore having the highest neutron shielding rate among the three boron ores studied was colemanite [10]. Characteristic analysis of shielding materials developed with zirconium borohydride and zirconium hydride and alloyed with $\mathrm{F} 82 \mathrm{H}$ alloy steel revealed that the zirconium borohydride shielding ability is lower. But when alloyed with steel, it has been seen that the ability of shielding increases. It has also been found that the steel alloy material is more effective in absorbing gamma rays that are caused by neutrons [11]. Metathesis-polymer matrix (DCPD) neutron shielding material, a thermoset resin developed using ${ }^{6} \mathrm{LiF}$, is specifically designed for use in boron neutron capture therapy [12]. 


\section{Materials and methodology}

Two basic features were considered when preparing the sample. One of these two properties is the physical condition of the neutron source used as a neutron source in shielding tests and the second is the need to make materials at different thickness ratios to determine the change in test results due to the increase in thickness. For this reason, three different specimens of 20,40 and $60 \mathrm{~mm}$ thickness were prepared by hand mixing with $70 \%$ by weight colemanite rate and poured into molds and then allowed to solidify. The colemanite used is the product of Eti Maden and has a size of 75-micron grain. The X-ray diffraction analysis report on the product and the TG / DTA analysis results indicating the temperature-dependent change are given in Figure 1 and Figure 2. Neutron shielding experiments of these samples were analyzed by isotropic neutron source Am-Be source and its counting system.

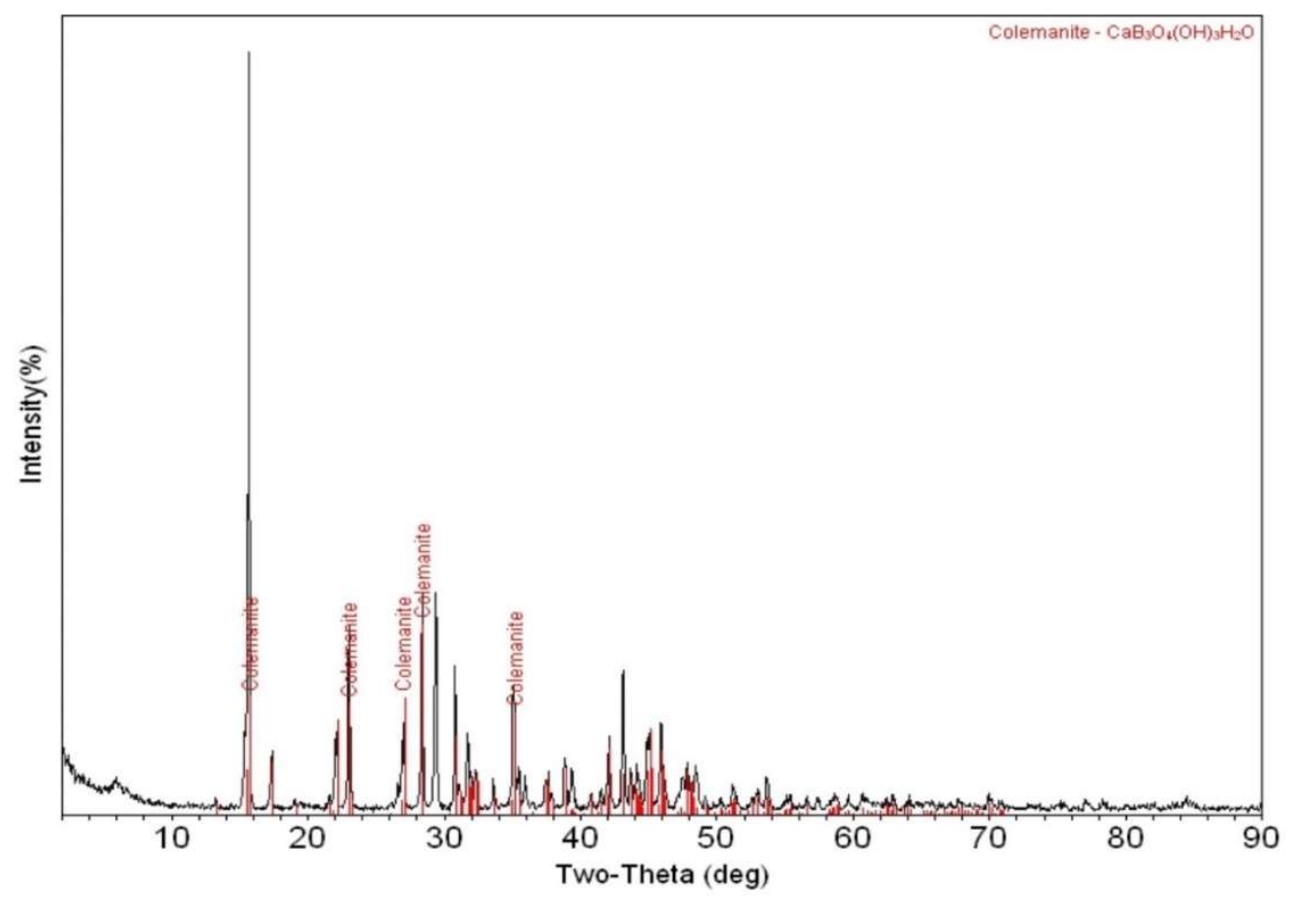

Figure 1. X-ray diffraction analysis of the Eti Maden colemanite [13]. 


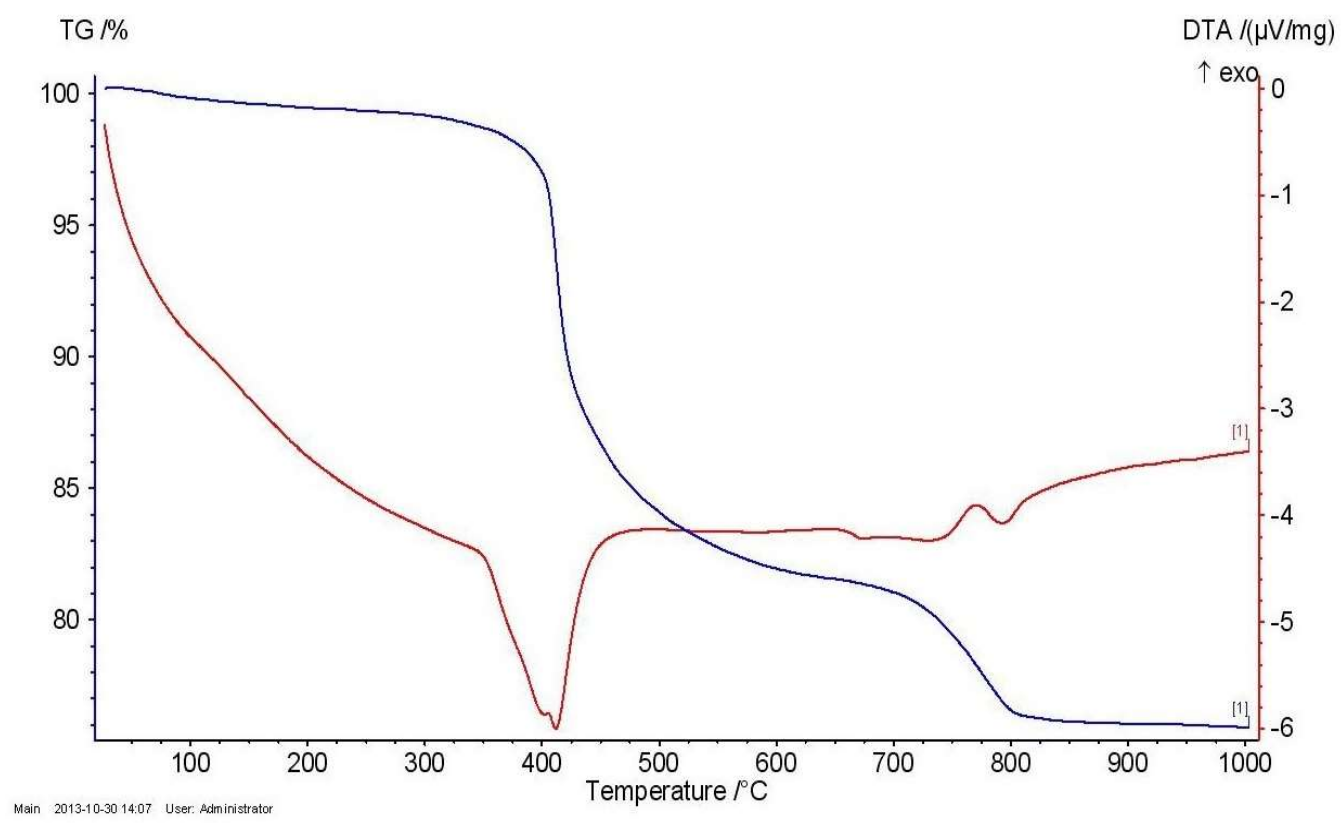

Figure 2. TG/DTA analysis of the Eti Maden colemanite [13].

The chemical analysis results of the colemanite are also given in Table 1.

Table 1. Chemical content analysis results of Eti Maden colemanite [13].

\begin{tabular}{|c|c|}
\hline $\mathbf{B}_{2} \mathbf{O}_{3}$ & $\% 40.00 \pm 0,50$ \\
\hline $\mathrm{CaO}$ & $\% 27.00 \pm 1$ \\
\hline $\mathrm{SiO}_{2}$ & $\% 4.00-6.50$ \\
\hline $\mathrm{SO}_{4}$ & $\% 0.60$ max. \\
\hline As & 35 ppm max. \\
\hline $\mathrm{Fe}_{2} \mathrm{O}_{3}$ & $\% 0.08$ max. \\
\hline $\mathrm{Al}_{2} \mathrm{O}_{3}$ & $\% 0.40$ max. \\
\hline MgO & \% 3.00 max. \\
\hline SrO & \% 1.50 max. \\
\hline $\mathrm{Na}_{2} \mathrm{O}$ & $\% 0.35$ max. \\
\hline Loss on Ignition & $\% 24.60$ max. \\
\hline Moisture & \% 1.00 max. \\
\hline Bulk Density & $1.00 \max$. ton $/ \mathrm{m}^{3}$ \\
\hline
\end{tabular}

\section{Experimental studies}

Neutron radiation shielding experiments were carried out using the obtained samples. The neutron source used in the study carried out with the Am-Be neutron source Howitzer and 
counting systems emits $4-5 \mathrm{MeV}$ energetic neutrons and its source activity is 2 Curie. The experimental set-up is shown in Figure $3 \mathrm{a}-\mathrm{b}$.

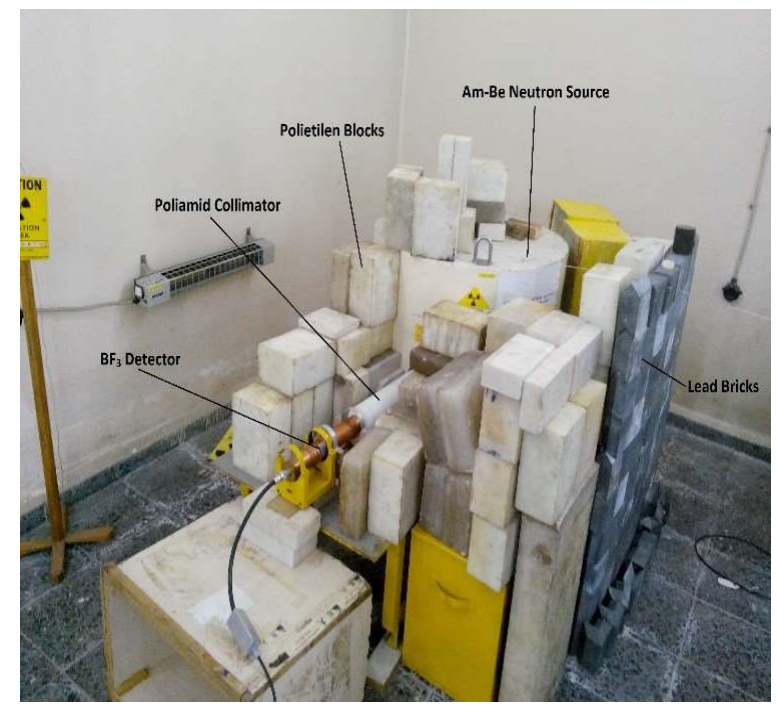

a)

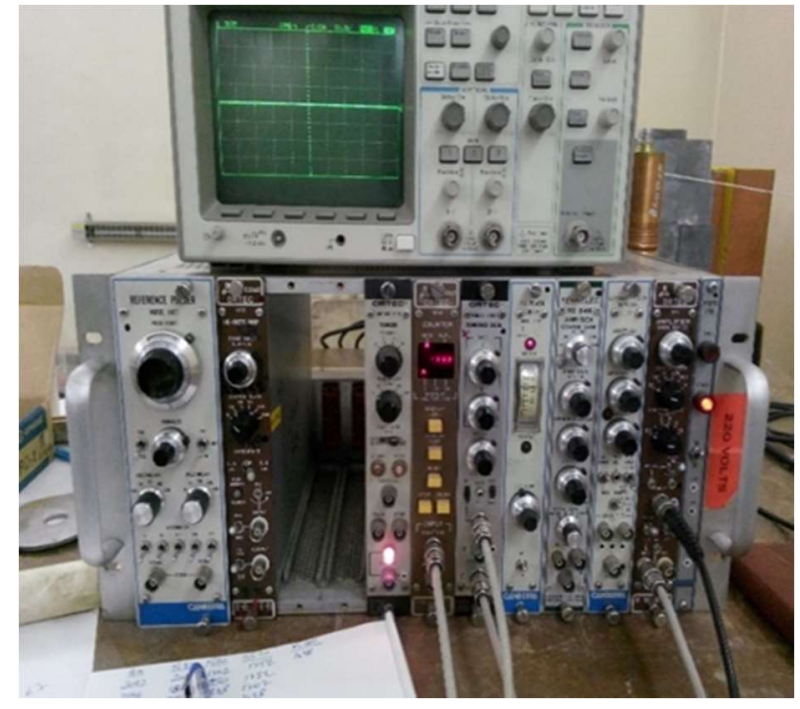

b)

Figure 3. a) Neutron source and detector system

b) Neutron source counting system

The list of equipment used in our test setup is given in Table 2.

Table 2. Equipment information used in neutron shielding test.

\begin{tabular}{|c|c|}
\hline Equipment & Property/Brand \\
\hline Neutron Source & ${ }^{241} \mathrm{Am}-{ }^{9} \mathrm{Be}$ \\
\hline Energy & $4-5 \mathrm{MeV}$ \\
\hline Activity & $2 \mathrm{Ci}$ \\
\hline Detector & Boron Trifluoride $\left(\mathrm{BF}_{3}\right)$ Neutron Detector \\
\hline Oscilloscope & Hewlett Packard \\
\hline Counter & Ortec 875 \\
\hline Timing \& SCA & Ortec Model $420 \mathrm{~A}$ \\
\hline Preamplificator & Ortec \\
\hline Amplificator & Ortec 571 \\
\hline Power Supply & Canberra Model 3105 H.V. $0-5 \mathrm{kV}$ \\
\hline Counting Time Per Specimen & $5 \times 500$ sec. \\
\hline
\end{tabular}

The variation of the obtained shielding results with the variation of the thickness of the samples is given in Fig. 4. 


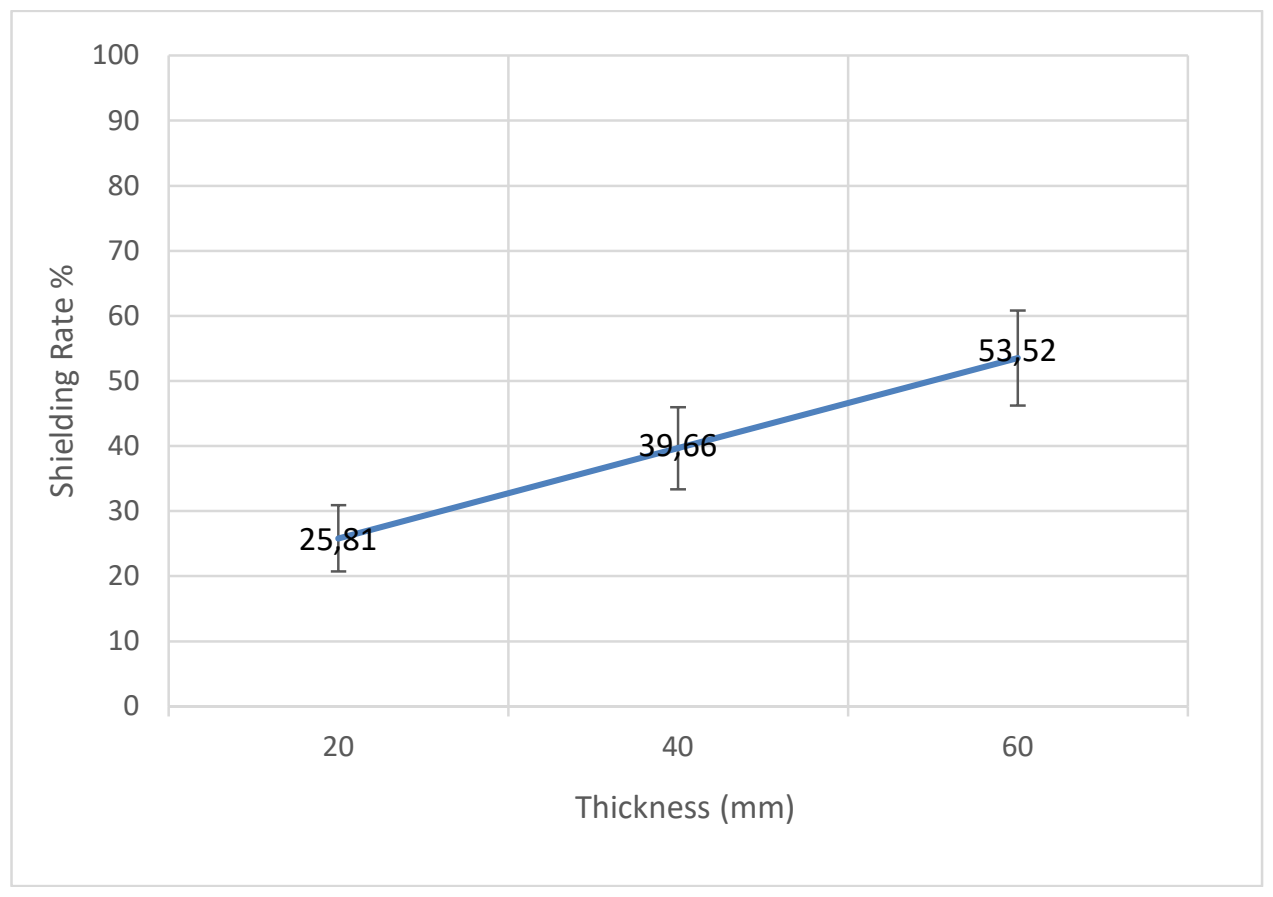

Figure 4. Neutron shielding results of $20-40-60 \mathrm{~mm}$ thick specimens containing $70 \%$ colemanite by weight.

\section{Conclusion}

Neutron shielding tests of specimens prepared at different thicknesses with a mixture of colemanite and concrete were performed experimentally. Containing $70 \%$ by weight of colemanite a boron compound 20,40 and $60 \mathrm{~mm}$ samples were prepared and their neutron shielding properties were studied. Composite material prepared by hand mixing. According to experimental results, as the thickness of the shielding material increases, the neutron shielding ratio of the composite material increases and colemanite reinforced concrete gives the results that can be used in fast neutron shielding applications. Likewise, the thickness of the shield must be determined according to the type of neutron source.

\section{References}

[1] Huang, Y., Liang, L., Xu, J., Zhang, W., The Design Study of a New Nuclear Protection Material, Nuclear Engineering and Design, 248 (2012): 22-27.

[2] Xu, Z.G., Jiang, L.T., Zhang, Q., Qiao, J., Gong, D., Wu, G.H., The design of a novel neutron shielding B4C/Al composite containing Gd, Materials and Design, 111 (2016): 375-381.

[3] Kharita, M.H., Yousef, S., Alnassar, M., Review on the Addition of Boron Compounds to Radiation Shielding Concrete, Progress in Nuclear Energy, 53 (2010): 207-211.

[4] Soltani, Z., Beigzadeh, A., Ziaie, F., Asadi, İ., Effect of particle size and percentages of Boron carbide on the thermal neutron radiation shielding properties of HDPE/B4C composite: Experimental and simulation studies , Radiation Physics and Chemistry, 127 (2016): 182-187.

[5] http://www.boren.gov.tr/tr/bor/bor-rezervleri 
[6] Sarıyer, D., Küçer, R., Küçer, N., Neutron Shielding Properties of Concretes Containing boron carbide and ferro boron, Procedia, Social and Behavioral Sciences, 195 (2015): 1752-1756.

[7] Kıpçak, A.S., Gürses, P., Derun, E.M., Tuğrul, N., Pişkin, S., Characterization of Boron Carbide Particles and Its Shielding Behavior, Energy Conversion and Management, 72 (2013): 39-44.

[8] Kharita, M.H., Yousef, S., Alnassar, M., Review on the Addition of Boron Compounds to Radiation Shielding Concrete, Progress in Nuclear Energy, 53 (2010): 207-211.

[9] Singh, V.P., Badiger, N.M., Gamma ray and neutron shielding properties of some alloy materials , Annals of Nuclear Energy, 64 (2013): 301-310.

[10] Korkut, T., Karabulut, A., Budak, B., Aygün, A., Gencel, O., Hançerlioğulları, A., Investigation of Neutron Shielding Properties on Number of Boron Atoms For Colemanite, Ulexite and Tincal Ores By Experiments and Fluka Monte Carlo Simulations, Applied Radiation and Isotopes, 70 (2013): 341-345.

[11] Hayashi, T., Tobita, K., Nakamori, Y., Orimo, S, Advanced Neutron Shielding Material Using Zirconium Borohydride and Zirconium Hydride, Journal of Nuclear Materials, 386, 388 (2009):119-121.

[12] Sakurai, Y., Sasaki, A., Kobayashi, T., Development of Neutron Shielding Material Using Metathesis-Polymer Matrix, Nuclear Instruments \& Methods in Physics Research, A522 (2003):455-461.

[13] http://www.etimaden.gov.tr/files/files/OGUTULMUS\%20KOLEMANIT.pdf/ 